\title{
Prioritering i global helse 果
}

\author{
Når ressursene er begrenset, må man prioritere. Hvilke tiltak som bør prioriteres, avhenger bl.a. av helse- \\ gevinst, prognosetap, helseulikhet og kostnad. Disse faktorene må veies opp mot hverandre. Det finnes \\ en rekke metoder som kan bidra til bedre global fordeling av helsetjenester. I denne artikkelen beskriver \\ vi kriterier for prioritering av helsearbeidet globalt og prioriteringsdilemmaer.
}

Engelsk oversettelse av hele artikkelen på www.tidsskriftet.no

\section{Kristine Bærøe}

kristine.baroe@ifikk.uio.no

Trygve Ottersen

Kristiane Eide

Hilde Engjom

Kjell Arne Johansson

Ingrid Miljeteig

Kristine Husøy Onarheim

Ole Frithjof Norheim

Forskningsgruppe for global helse:

etikk, økonomi \& kultur

Institutt for samfunnsmedisinske fag

Universitetet i Bergen

Leger og annet helsepersonell, helseplanleggere, politikere og bistandsorganisasjoner avgjør på ulike beslutningsnivåer hvordan midlene som skal brukes på helse skal fordeles. Et fundamentalt spørsmål ved prioriteringer er hvilke kriterier som bør gjelde. Når det gjelder global helse, har særlig kostnadseffektivitet stått sentralt (1). Det er imidlertid betydelig oppslutning i akademisk litteratur om relevansen av et bredere sett av kriterier for prioritering av helseintervensjoner (ramme 1) (1-4). Det er mindre grad av enighet om hvordan disse kriteriene skal spesifiseres ved anvendelse og hvordan de skal vektes i forhold til hverandre.

Det finnes også en rekke andre kriterier, som er omstridte. Disse er knyttet til blant annet alder, kjønn, sosial status, den enkeltes ansvar for sin egen helsetilstand, nytte for familie og samfunn og - ikke minst - betalingsevne.

\section{To eksempler}

Generelle kriterier av typen som er beskrevet over er relevante for nesten all praksis innen global helse. De følgende to eksemplene illustrerer hvordan konflikten mellom generelle kriterier kan komme til uttrykk og hvordan ikke-kontroversielle kriterier kan stå i motsetning til gjeldende praksis.

\section{Effekt versus alvorlighetsgrad}

Indikasjonen for oppstart av antiretroviral behandling (ART) for pasienter med hiv har tradisjonelt vært CD4-tall $<200$ celler/ $\mu$ l.
Verdens helseorganisasjon (WHO) endret sommeren 2010 sine retningslinjer slik at oppstart av behandling nå også er indisert ved CD4-tall i området 200-350 celler/ $\mu 1$ (5). De fleste lavinntektsland har implementert de nye retningslinjene, med unntak av Etiopia og Thailand. Disse retningslinjene representerte et fundamentalt skifte - med endringen i biokjemisk indikasjon fulgte en endring i vektlegging av prioriteringskriterier. Pasienter med CD4-tall i området 200-350 celler/ $\mu 1$ har større effekt (målt $i$ vunne leveår) av behandling enn pasienter med CD4-tall $<200$ celler/ $\mu$ l (fig 1) (6). De sistnevnte er imidlertid sykere.

Ut fra effektkriteriet fremstår indikasjonsendringen som berettiget. Ut fra alvorlighetsgradskriteriet burde imidlertid alle med CD4-tall $<200$ celler/ $\mu$ l fătt tilbud om behandling før man utvidet indikasjonen for antiretroviral behandling til 350 celler $/ \mu 1$. I dag får kun $52 \%$ av dem med CD4-tall $<200$ celler/ $\mu 1$ et slikt tilbud (7). Vi ser her en konflikt mellom anbefalingene som følger av effektkriteriet og anbefalingene som følger av alvorlighetsgradskriteriet. Thailand og Etiopia har valgt å sørge for full dekningsgrad av antiretroviral behandling til de sykeste før de oppskalerer til behandling av dem med høyere CD4-tall, som altså har best effekt av den.

\section{Prioritering av sykehusbehandling for premature}

Inntil nylig har premature i ressursfattige land fått liten oppmerksomhet (8). I India blir det årlig født mer enn en halv million barn i eller før svangerskapsuke 32. Svært få av disse får behandling og overlever. Med sykehusbehandling ville $90 \%$ av disse barna født i uke 30-32 overleve (9). Kostnaden per kvalitetsjustert leveår er lavere enn det de indiske myndighetene ellers dekker for andre pasientgrupper $(10,11)$.

Sykehusbehandling av premature synes å oppfylle alle de generelle kriteriene for rettferdig prioritering: tilstanden er alvorlig, effekten er god, ulikheten i livslengde reduseres og tiltaket er kostnadseffektivt. Et prematurt barn med risiko for senere svekket

\section{«Rettferdig prioritering - Lokalt og globalt - forutsetter kunnskap o m hvordan helsenivået er i forskjellige grupper i befolkningen»}

helse og funksjonshemninger vil imidlertid kunne medføre katastrofale helseutgifter for familien. Helsepersonell oppgir at fremtidige helseutgifter og hensynet til familiens velferd er avgjørende grunner for å avstå fra behandling (9). Dette eksemplet illustrerer hvor viktig det er å studere også velferdskonsekvenser av prioritering.

\section{Verktøy for informerte valg}

Globalt sett er dekningsgraden av mange helsetiltak ofte lav, til tross for at vi har god kunnskap om hva som fremmer helse og hindrer sykdom innen for eksempel barne-

\section{Ramme 1}

\section{Kriterier for prioritering} av helseintervensjoner

- Effektkriteriet: Høyere prioritet desto større helsegevinst fra intervensjonen

- Alvorlighetsgradskriteriet: Høyere prioritet desto større prognosetap for målgruppen uten intervensjon

- Likhetskriteriet: Høyere prioritet desto lavere forventet helse over hele livsløpet i forhold til andre deler av befolkningen. Indirekte kan en mengde faktorer spille inn, inkludert alvorlighetsgrad, alder og sosioøkonomisk status

- Kostnad-effekt-kriteriet: Høyere prioritet desto lavere intervensjonskostnad i forhold til effekt 
og mødrehelse (11-14). Dette skyldes blant annet manglende finansiering.

Nylig er det utviklet beregningsverktøy, eksempelvis Lives Saved Tool og Marginal Budgeting for Bottlenecks, som gjør det mulig å modellere virkningen av ulike helsetiltak $(15,16)$. Lives Saved Tool integrerer epidemiologiske data om dødelighet med effektdata og gjør det lettere for beslutningstakere å sammenlikne antall sparte liv ved ulike intervensjoner for barne- og mødrehelse (15). Ved å legge inn lokale data om dødelighet og dekningsgrad kan man vurdere hvilke intervensjonspakker som gir best resultater ut fra tilgjengelige midler (17).

\section{Verktøy for å måle helseulikhet}

Rettferdig prioritering - lokalt og globalt forutsetter kunnskap om hvordan helsenivået er i forskjellige grupper i befolkningen. Lik helse over livsløpet, så langt det er mulig, er et mål for de fleste helsesystemer. Den globale sykdomsbyrden er ulikt og urettferdig fordelt mellom ulike land (18). I tillegg er sykdomsbyrden innad i hvert land også ulikt og urettferdig fordelt geografisk og etter sosial status målt ved inntekt, utdanning og, i mange tilfeller, kjønn (19).

Helseulikheter kan måles ved Giniindeksen, opprinnelig brukt som et mål på økonomisk ulikhet (20). Den gir et relativt mål på ulikhet innenfor en populasjon uttrykt i verdier fra 0 til 1 , der 1 er maksimal ulikhet. Man kan for eksempel måle hvor stor ulikhet i levealder det er i befolkningen (21). Særlig i lavinntektsland ser man at en relativt høy andel av dødsfallene inntreffer hos barn og yngre voksne. Fordelingen av leveår blir da svært ulik. I 1990 var for eksempel barnedødeligheten i Etiopia 202 per 1000 (22). Det vil si at mer enn $20 \%$ av alle fødte barn ikke fylte fem år.

Et land som Etiopia har hatt stor nedgang i barnedødeligheten (22). Dette fører til $ø \mathrm{kt}$ forventet levealder og redusert ulikhet i forventet levealder (Gini-helse). Figur 2 viser at forventet levealder ved fødselen i Etiopia økte fra 48 år i 1990 til 58 år i 2008 (23). Landet er på god vei til å nå FNs tusenårsmål nr. 4 (to tredels reduksjon i barnedødeligheten i 2015), og den forventede levealderen vil dermed gå opp, til 60 år.

Gini-helseindeksen ble redusert fra 0,35 i 1990 til 0,25 i 2008 og vil bli ytterligere redusert til 0,22 dersom tusenårsmålet nås. Gini-helse er et relativt mål på ulikhet som også kan omregnes til absolutte tall. Absolutt Gini-helse var i 2008 26,3. Det vil si at det forventede avvik fra gjennomsnittlig antall forventede leveår var 26,3 år. Dette er en betydelig ulikhet. Samlet sett viser likevel figur 1 at det har skjedd store positive forbedringer i Etiopia og at denne utviklingen kan måles og evalueres på populasjonsnivå.

\section{Prioriteringsprosedyrer}

Fordeling av knappe helseressurser skaper vinnere og tapere. De globale helseinitia- tivene har alle ulike prioriteringer. Hva skal til for at beslutningstakere tilkjennes moralsk autoritet til å avgjøre kontroversielle prioriteringsspørsmål? En filosofisketisk tilnærming til dette spørsmålet er basert på en antakelse om at det vil være mindre problematisk å oppnå enighet om generelle betingelser for en rettferdig beslutningsprosedyre enn om spesifikke prinsipper for en rettferdig fordeling. Beslutningsprosesser utført i overensstemmelse med betingelser for rettferdig håndtering av moralsk uenighet gir beslutningene mer legitimitet.

Filosofen Norman Daniels \& psykiateren James Sabin har utviklet et rammeverk for legitim fordeling av helseressurser (24). Rammeverket Accountability for Reasonableness (A4R, eller «ansvarlighet for rimelig begrunnelser») består av fire betingelser som sammen skal sikre en velbegrunnet og legitim beslutningsprosess:

- Begrunnelser for prioriteringsbeslutningen må være åpne, publiseres og gjøres tilgjengelig for alle interesserte

- Relevansen av kriteriene for beslutningen må etableres gjennom grundige overveielser og være basert på enighet blant alle berørte parter

- Det må foreligge klagerett, og beslutningen må kunne revideres

- Det må foreligge frivillig eller offentlig regulering som påser at de tre forutgående betingelsene er møtt

Rammeverket tilrettelegger for verdivalg ved prioritering på en måte som alle kan leve med. I dette perspektivet fremstår trolig A4R som den mest lovende prosedurale tilnærmingen vi har sett så langt.

\section{Prioriteringer i global helse og Norges bidrag}

Den globale sykdomsbyrden, målt i kvalitetsjusterte leveår (disability adjusted life years, DALY) viser at nesten $40 \%$ av tapte leveår skyldes smittsomme sykdommer,

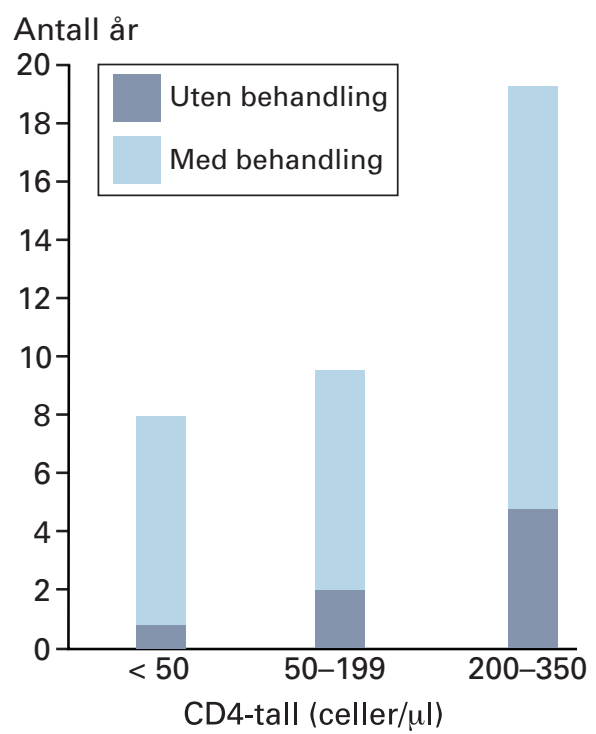

Figur 1 Forventet antall gjenværende leveår i lavinntektsland for hivpasienter med ulike CD4-tall med eller uten antiretroviral behandling (6)

ernæringsrelaterte tilstander og sykdommer i forbindelse med fødsel (18). Kroniske sykdommer forårsaker nesten $35 \%$ av tapte kvalitetsjusterte leveår (18). Forskningsaktiviteten gjenspeiler ikke dette, ettersom majoriteten av midlene brukes til å forske på tilstander som rammer mindretallet.

Studier av de globale helseinitiativene viser at tilgjengelige forsknings- og behandlingsressurser ikke står i forhold til sykdomsbyrden. Dette gjelder særlig mødre- og nyfødthelse, som relativt sett har fått mindre oppmerksomhet enn hiv/aids (25-28).

Innen helsetjenesten har de globale helseinitiativene med implementering av utvalgte behandlingsprogrammer ført til svekkelse av helsetjenestens evne til å gi et helhetlig tilbud til alle (29). Selv vaksineprogrammer når i mindre grad frem til de fattigste (30). Til tross for at de utgjør en stor del av den samlede sykdomsbyrde, har områder som mental helse og ikke-smittsomme syk-

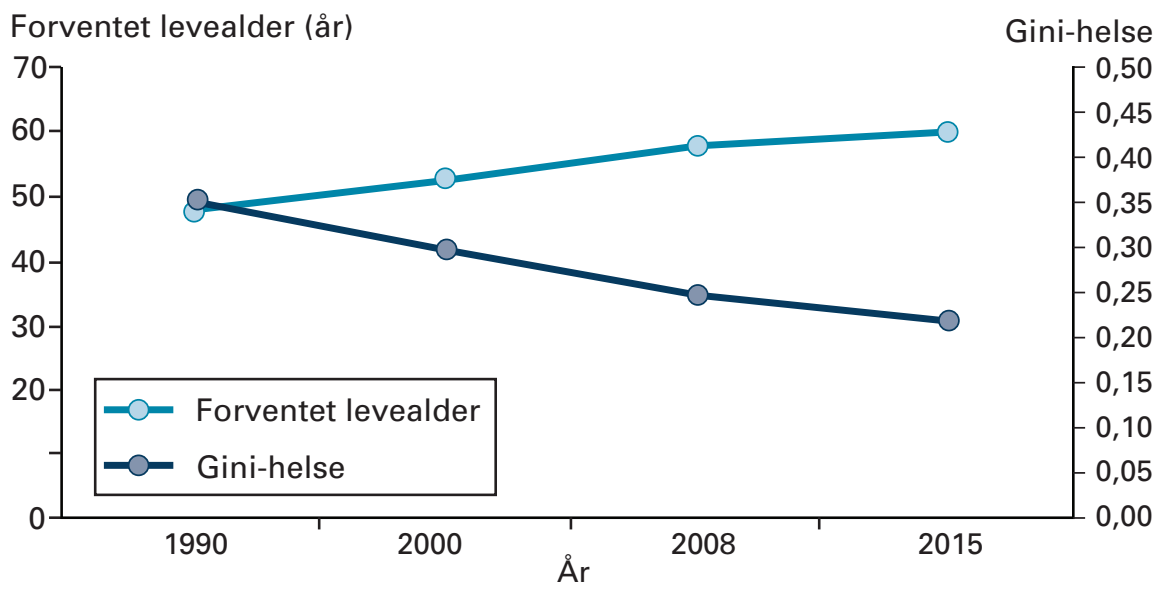

Figur 2 Forventet levealder ved fødsel i Etiopia og Gini-helse i 1990, 2000, 2008 og 2015 (dersom tusenårsmålet nås). Gini-helse er et relativt mål på ulikhet i helse innenfor en populasjon. Måleskalaen går fra 0 til 1 , der 1 uttrykker maksimal ulikhet (egne utregninger) (23) 
dommer ikke vært gjenstand for bred oppmerksomhet før inntil nylig. Vi vet at det finnes kostnadseffektive tiltak som kan redusere sykdomsbyrden innen flere av disse områdene. Manglende prioritering medfører derfor tapte muligheter når det gjelder en mer effektiv og rettferdig fordeling av ressursene.

Norge er en stor bistandsaktør. Over $1 \%$ av bruttonasjonalinntekten går til bistand, hvor ca. $7 \%$ av midlene ( 2 milliarder) i 2010 gikk til bistand tilknyttet helse- og sosialsektoren (31). Bistanden de siste årene har vært sentrert rundt investeringer i multinasjonale bistandsorganisasjoner, frivillige organisasjoner og budsjettstøtte til enkeltland (31). Bistandsmidlene knyttes nå opp mot FNs tusenårsmål, inkludert behandling for hiv/aids $(32,33)$. Vi mangler imidlertid kunnskap om hvilken betydning dette har for en mer rettferdig fordeling av helseressursene. Vi savner åpne, kunnskapsbaserte prosesser for rettferdige prioriteringer, både i Norge og globalt.

\section{Kristine Bærøe (f. 1971)}

er filosof med ph.d. i medisinsk etikk. Hun er for tiden postdoktor ved Etikkprogrammet ved Universitetet i Oslo.

Ingen oppgitte interessekonflikter.

\section{Trygve Ottersen (f. 1982)}

er turnuslege ved Haukeland universitetssykehus og doktorgradsstudent. Han har en bachelorgrad i filosofi.

Ingen oppgitte interessekonflikter.

\section{Kristiane Tislevoll Eide (f. 1989)}

er medisinstudent og forskerlinjestudent i forskningsgruppen for Etikk og prioritering. Hun forsker på ulikheter i barnehelse i lavinntektsland

Ingen oppgitte interessekonflikter.

\section{Hilde Engjom (f. 1974)}

er lege i spesialisering ved Kvinneklinikken i Bergen og forsker ved Institutt for samfunnsmedisin. Hun hatt tatt diplomkurs i tropemedisin i Liverpool. Engjom er leder av Legeforeningens utvalg for internasjonal helse. Ingen oppgitte interessekonflikter.

\section{Kjell Arne Johansson (f. 1975)}

er lege i spesialisering ved Kvinneklinikken i Bergen og ansatt ved Helse Vest på prosjektet «Prioritering på tvers av kliniske fagområder». Han har en ph.d. i medisinsk etikk og global helse.

Ingen oppgitte interessekonflikter.

\section{Ingrid Miljeteig (f. 1975)}

har doktorgrad i medisinsk etikk med vekt på kliniske beslutninger og prioritering. Hun er turnuslege og rådgiver i etikkomiteen ved Helse Bergen.

Ingen oppgitte interessekonflikter.

\section{Kristine Husøy Onarheim (f. 1987)}

er medisinstudent og forskerlinjestudent ved Universitetet i Bergen. Hun har også studert global helse samme sted.

Ingen oppgitte interessekonflikter.

\section{Ole Frithjof Norheim (f. 1965)}

er professor i medisinsk etikk ved Institutt for samfunnsmedisinske fag, Universitetet i Bergen, og har ledet prosjektet «The ethics of priority setting in global health» (2005-11) finansiert av Norges forskningsråds pris for yngre fremragende forskere.

\section{Litteratur}

1. Brock DW, Wikler D. Ethical issues in resource allocation, research, and new product development. I: Jamison DT, Breman JG, Measham AR et al, red. Disease control priorities in developing countries. 2. utg. New York: Oxford University Press, Verdensbanken, 2006: 259-70.

2. Daniels N. Just health: meeting health needs fairly. Cambridge: Cambridge University Press, 2008

3. Persad G, Wertheimer A, Emanuel EJ. Principles for allocation of scarce medical interventions. Lancet 2009. 373: 423-31.

4. Norheim OF. Clinical priority setting. BMJ 2008; 337: a1846

5. Antiretroviral therapy for HIV infection in adults and adolescents - recommendations for a public health approach - 2010 revision. Genève: WHO, 2010.

6. Johansson KA, Robberstad B, Norheim OF Further benefits by early start of HIV treatment in low income countries: survival estimates of early versus deferred antiretroviral therapy. AIDS Res Ther 2010; 7: 3 .

7. Towards universal access. Scaling up priority HIV/ AIDS interventions in the health sector. Progress report 2009 Genève. WHO, UNAIDS, Unicef, 2009

8. Kelley M, Rubens CE. Global report on preterm birth and stillbirth (6 of 7): ethical considerations. BMC Pregnancy Childbirth 2010; 10 (suppl 1): S6.

9. Miljeteig I, Sayeed SA, Jesani A et al. Impact of ethics and economics on end-of-life decisions in an Indian neonatal unit. Pediatrics 2009; 124: e322-8

10. Paul VK, Sachdev HS, Mavalankar D et al. Reproductive health, and child health and nutrition in India: meeting the challenge. Lancet 2011; 377 . $332-49$

11. Darmstadt GL, Bhutta ZA, Cousens S et al. Evidence-based, cost-effective interventions: how many newborn babies can we save? Lancet 2005 . 365: 977-88.

12. Jones G, Steketee RW, Black RE et al. How many child deaths can we prevent this year? Lancet 2003; 362: 65-71

13. Jamison DT, Breman JG, Measham AR et al, red. Disease control priorities in developing countries. 2. utg. New York: Oxford University Press, Verdensbanken, 2006

14. WHO-CHOICE. Choosing interventions that are cost effective. www.who.int/choice/en/ (2.8.2011).

15. Bryce J, Friberg IK, Kraushaar D et al. LiST as a catalyst in program planning: experiences from Burkina Faso, Ghana and Malawi. Int J Epidemiol 2010; 39 (suppl 1): i40-7.

16. Knippenberg R. Soucat A, Vanlerberghe W et al. Marginal Budgeting for Bottlenecks: a tool for per formance based planning of health and nutrition services for achieving millennium development goals. 2004. http://mdgr.undp.sk/PAPERS/ MBB \%20Concept \%20Paper.doc (2.8.2011)

17. Friberg IK, Kinney MV, Lawn JE et al. Sub-Saharan Africa's mothers, newborns, and children: how many lives could be saved with targeted health interventions? PLoS Med 2010; 7: e1000295.

18. Mathers C, Fat DM, Boerma JT. The global burden of disease : 2004 update. Genève: WHO, 2008.

19. Venkatapuram S, Marmot M. Epidemiology and social justice in light of social determinants of health research. Bioethics 2009; 23: 79-89.

20. Wagstaff A. Inequality aversion, health inequalities and health achievement. J Health Econ 2002; 21: 627-41.

21. Le Grand J. Inequalities in health. Some international comparisons. Eur Econ Rev 1987; 31 182-91.

22. Rajaratnam JK, Marcus JR, Flaxman AD et al. Neonatal, postneonatal, childhood, and under-5 mortality for 187 countries, 1970-2010: a systematic analysis of progress towards millennium development goal 4. Lancet 2010; 375: 1988-2008.

23. WHO life tables for member states 2008. http://apps.who.int/whosis/database/life_tables/ life_tables.cfm (1.10.2009).

24. Daniels N, Sabin J. Setting limits fairly. Can we earn to share medical resources? Oxford: Oxford Univeristy Press, 2002.

25. Shiffman J. Donor funding priorities for communi cable disease control in the developing world. Health Policy Plan 2006; 21: 411-20

26. Piva P. Dodd R. Where did all the aid go? An indepth analysis of increased health aid flows over the past 10 years. Bull World Health Organ 2009; 87: $930-9$.

27. Shiffman J. HIV/AIDS and the rest of the global health agenda. Bull World Health Organ 2006; 84 923

28. Powell-Jackson T, Borghi J, Mueller DH et al. Countdown to 2015: tracking donor assistance to maternal, newborn, and child health. Lancet 2006 368: 1077-87.

29. Samb B, Evans T, Dybul M et al. An assessment of interactions between global health initiatives and country health systems. Lancet 2009; 373 : 2137-69.

30. Countdown to 2015. Decade report (2000-2010): Taking stock of maternal, newborn and child survival. Genève: WHO, Unicef, 2010

31. Bistandsstatistikken 2010. Oslo: NORAD, 2010. www.norad.no/Norskbistanditall/Statistikkvisning (11.4.2011)

32. Health FG. 2010: Development assistance and country spending in economic uncertainty. Seattle: Institute for Health Metrics and Evaluation, 2010.

33. Ravishankar N, Gubbins P, Cooley RJ et al. Financing of global health: tracking development assis tance for health from 1990 to 2007. Lancet 2009; 373: $2113-24$

Mottatt 22.6. 2011, først revisjon 2.8. 2011, godkjent 4.8. 2011. Medisinsk redaktør Trine B. Haugen. 